\title{
Association between cardiorespiratory fitness and the prevalence of metabolic syndrome among Korean adults: a cross sectional study
}

Sunghyun Hong ${ }^{1,2+}$, Junga Lee ${ }^{1,2+}$, Jihye Park ${ }^{1,2}$, Mikyung Lee ${ }^{1,2}$, Ji Young Kim 1,2, Kyong-Chol Kim³ ${ }^{3}$ Sun Hyun Kim², Jee Aee $\mathrm{Im}^{5}$, Sang Hui Chu ${ }^{6}$, Sang Hoon Suh ${ }^{7}$, Sang Hwan $\mathrm{Kim}^{8}$ and Justin Y Jeon ${ }^{1,2^{*}}$

\begin{abstract}
Background: The purpose of the current study was to investigate the association between cardiorespiratory fitness (CRF), measured by a simple step test, and the prevalence of metabolic syndrome among Korean adults, in a cross sectional design.

Methods: A total of 1,007 Korean adults (488 men and 519 women) who underwent routine health checkups were recruited. CRF was measured by Tecumseh step test. The National Cholesterol Education Program's Adult Treatment Panel III guideline was used to determine the prevalence of metabolic syndrome. A logistic regression was performed to reveal possible associations.

Results: The results of the study showed that a lower level of CRF was significantly associated with a higher prevalence of metabolic syndrome in men, but not in women. On the other hand, higher BMI was associated with a higher prevalence of metabolic syndrome in both men and women. However, BMI was not associated with fasting glucose nor hemoglobinA1c in men. When the combined impact of BMI and CRF on the prevalence of metabolic syndrome was analyzed, a significantly increased prevalence of metabolic syndrome was found in both men (odds ratio [OR]: 18.8, 95\% Confidence Interval [Cl]: 5.0 - 70.5) and women (OR: 8.1, 95\% Cl: 2.8 - 23.9) who had high BMI and low cardiorespiratory fitness. On the other hand, the prevalence of metabolic syndrome was only increased 7.9 times (95\% Cl: 2.0 - 31.2) in men and 5.4 times (95\% Cl: 1.9 - 15.9) in women who had high level of CRF and high BMI.

Conclusion: In conclusion, the current study demonstrated the low CRF and obesity was a predictor for metabolic syndrome in Korean adults.
\end{abstract}

Keywords: Cardiorespiratory fitness, Simple step test, Obesity, Metabolic syndrome, Korean adults

\section{Background}

Metabolic syndrome, also known as insulin resistance syndrome or syndrome $\mathrm{X}$, is the term most commonly used to identify a constellation of metabolic disorders [1]. In 2001, the National Cholesterol Education Program's Adult Treatment Panel III (NCEP: ATP III) defined metabolic syndrome as having three of the five following components:

\footnotetext{
* Correspondence: jjeon@yonsei.ac.kr

${ }^{\dagger}$ Equal contributors

'Department of Sport and Leisure Studies, Sport Medicine Laboratory, Yonsei

University, Seoul, Korea

2Exercise Medicine Center for Diabetes and Cancer Patients, Yonsei

University, Seoul, Korea

Full list of author information is available at the end of the article
}

glucose intolerance, hypertension, insulin resistance, abdominal obesity, and dyslipidemia [2]. Metabolic syndrome is associated with an increased risk of type 2 diabetes [3-5] and cardiovascular disease (CVD) $[4,6]$.

Over the last few decades, the prevalence of metabolic syndrome has increased worldwide, and it has become a major public health concern in many countries, including several Asian countries [7-9]. According to data from the Korean National Health and Nutrition Examination Survey (KNHANES, 1998-2007), the age-adjusted prevalence of metabolic syndrome among Korean adults rapidly increased from $24.9 \%$ in 1998 to $31.3 \%$ in 2007 [9]. The rise in the prevalence of metabolic syndrome was related to 
both an increased prevalence of obesity $[10,11]$ and decreased physical activity levels [12-14].

A low level of cardiorespiratory fitness (CRF) is a major contributing risk factor for metabolic syndrome [15-17], as well as a predictor of overall mortality [18-22]. Other studies showed that a high level of CRF is associated with a significantly reduced incidence of metabolic syndrome [15,23-25]. Thus, maintaining and improving CRF is an important strategy for the prevention of metabolic syndrome.

While several studies have indicated that increased $\mathrm{CRF}$ and decreased BMI reduced the risk of metabolic syndrome $[15,24]$ the current study is one of the first studies to explore the combined association of BMI and CRF with the prevalence of metabolic syndrome in Korean adults. Most previous studies have used maximal oxygen consumption (VO2 max) to measure CRF, which has been the gold standard measurement for CRF [26]. However, this method is challenging due to the high cost of the equipment required and the need for trained personnel. For this reason, heart rate during or after submaximal exercise has been used as an alternative method to measure CRF in large epidemiological studies $[24,27,28]$. Furthermore, the step test has been proven to be safe and inexpensive, and therefore can be used in the clinic for patients with a history of cardiac events, as well as in situations where the equipment needed to perform the $\mathrm{VO} 2$ max test is not available.

Therefore, the purpose of this study was to analyze the association between CRF, measured by heart rate recovery (HRR) after the step test, and the prevalence of metabolic syndrome in Korean adults. We further analyzed the combined association of BMI and CRF with the prevalence of metabolic syndrome.

\section{Methods}

\section{Ethical considerations}

The study was approved by the Ethics Review Committee of MizMedi Hospital.

\section{Participants}

The study recruited 1,007 Korean adults (488 men and 518 women) who visited the Health Care Center at Myongji University Hospital for general health examination between November 2008 and February 2009. The purpose of this study was explained to all participants, and written consent was obtained from all participants prior to their participation. Potential participants were excluded if they had experienced excessive body weight gain or loss (approximately $\pm 5 \mathrm{~kg}$ ) during the past three months, or if they required additional medical monitoring due to cardiac or cancer-associated surgery during the past three months.

\section{Anthropometric and biochemical data Anthropometric measurements}

Height and weight were measured to the nearest $0.1 \mathrm{~cm}$ and $0.1 \mathrm{~kg}$ (JENIX DS-102; DONG SAHN JENIX Co Ltd, Seoul, Korea), with the participants barefoot and in light clothing. Body mass index (BMI) was calculated as weight (kilograms) divided by height (meters squared). Waist circumference (WC) was measured at the midpoint between the bottom of the rib cage and the top of the lateral border of the iliac crest with participants in the standing position at the end of a normal expiration. Blood pressure was measured twice at a five-minute interval. Blood pressure readings were taken from the right arm, after a rest period, by use of a sphygmomanometer (HM-1101; HICO Co Ltd, Tokyo, Japan).

\section{Blood specimens}

Blood samples were collected in the morning after participants had been seated for 30 minutes and had fasted overnight (at least 12 hours). Serum fasting glucose, total cholesterol (TC), triglycerides (TG), and high-density lipoprotein (HDL) were measured using an ADVIA 1650 Chemistry Analyzer System (Siemens, Tarrytown, NY, USA). Hemoglobin A1c (HbA1c) was evaluated using an HLC-723GHb (TOSOH, Siba, Japan).

\section{Definition of metabolic syndrome}

This study used the National Cholesterol Education Program Adult Treatment Panel III (NCEP-ATP III) guidelines [2] to determine the presence of metabolic syndrome. Abdominal obesity was determined by waist circumference. To address ethnic and regional factors in the diagnostic criteria, abdominal obesity was defined by the Asia-Pacific criteria for waist circumference (APC-WC) [29]. The study used the recent International Diabetes Federation (IDF) metabolic syndrome definition [30], which includes criteria established by the NCEP: ATP III and the APC-WC. Participants were considered to have metabolic syndrome if three or more of the following five criteria were met: 1) high blood pressure ( $\geq 130 / 85 \mathrm{mmHg}$ ); 2) hyperglycemia (fasting plasma glucose $\geq 100 \mathrm{mg} / \mathrm{dL}$ ); 3) hypertriglyceridemia ( $\geq 150 \mathrm{mg} / \mathrm{dL}) ; 4)$ low HDL cholesterol $(<40 \mathrm{mg} / \mathrm{dL}$ in men, $<50 \mathrm{mg} / \mathrm{dL}$ in women); and 5) abdominal obesity (waist circumference $\geq 90 \mathrm{~cm}$ for men, $\geq 80 \mathrm{~cm}$ for women).

\section{Assessment of CRF}

All participants underwent the Tecumseh step test to determine their CRF values. The test was performed on a step/bench $20.3 \mathrm{~cm}$ (8 inches) in height, for a duration of three minutes at a 24-cycle per minute rate, as controlled by a metronome [31]. One stepping cycle consisted of four steps: right foot UP, left foot UP, right foot DOWN, and left foot DOWN. Immediately following the three minutes 
of exercise, participants rested in a sitting position. The test procedure was demonstrated and explained to the participant before the onset of the exercise. Participants wore a heart rate monitor (Polar-FS3c, USA). Resting heart rates were measured prior to the test and at oneminute intervals during exercise, and then again one minute after termination of the exercise. The study defined HRR as the heart rate (beats/min) measured one minute after exercise. For analysis purposes, the participants' data were separated on the basis of gender and categorized into one of three groups according to CRF tertile.

\section{Statistics}

From the distribution of measurements calculated for body mass and fitness levels, the BMI and CRF values were divided into low, middle, and high groupings [32,33]. In men, the mean of low, middle, and high tertiles for BMI and CRF represented 21.7 (range 17.1 to 23.6), 24.7 (23.7 to 25.7 ), 27.4 (25.8 to 34$) \mathrm{kg} / \mathrm{m}^{2}$ and 74.7 (53 to 82 ), 87.6 (83 to 93 ), 104.5 (94 to 137 ) beats/min, respectively; in women, the low, middle, and high tertiles for BMI and CRF represented 20.1 (15.9 to 21.4), 22.7 (21.5 to 24), 26.7 (24.1 to 35.6$) \mathrm{kg} / \mathrm{m}^{2}$ and 79.8 (65 to 86 ), 92.4 (87 to 97 ), 108.2 (98 to 133 ) beats/min, respectively. Overall, participants were divided into nine groups: (1) low BMI and low CRF, (2) low BMI and middle CRF, (3) low BMI and high CRF, (4) middle BMI and low CRF, (5) middle BMI and middle CRF, (6) middle BMI and high CRF, (7) high BMI and low CRF, (8) high BMI and middle CRF, and (9) high BMI and high CRF, to investigate the relationships between metabolic syndrome, BMI and CRF.

The normality of the data was tested using the ShapiroWilk test. The parameters' normality was compared with the Student's t-test, and the nonparametric Mann-Whitney test was conducted for non-normally distributed variables. Statistical comparisons among the tertile groups for HRR and BMI were performed using one-way analysis of variance (ANOVA) followed by a post-hoc Scheffe for men and analysis of covariance (ANCOVA) with post-hoc Bonferroni for women, respectively. To determine the association of metabolic syndrome prevalence with CRF and BMI, logistic regression analyses were performed after adjusting for age. Metabolic syndrome was assigned as a dependent variable, and age, HRR and BMI were assigned as independent variables. A two-sided analysis with $p<0.05$ was considered statistically significant. All data are presented as mean \pm standard deviation (SD) and percentages. All statistical analyses were conducted using SPSS version 18.0 for Windows.

\section{Results}

\section{Clinical characteristics}

The anthropometric and biochemical characteristics of participants in this study are summarized in Table 1. Of the 1,007 participants, $110(22.9 \%)$ of the 488 men, and 119 (23.1\%) of the 518 women had metabolic syndrome.

\section{Association between CRF and metabolic syndrome}

Anthropometric and metabolic parameters according to tertile of HRR after step exercise are presented in Table 2. There was no difference in any of the anthropometric components among the groups. The fasting glucose level was significantly higher and the high-density lipoprotein (HDL-C) was significantly lower in the low CRF group compared with those in the moderate and high CRF groups $(p<0.05)$. The low CRF group had a significantly higher number of participants with metabolic syndrome when compared to the high CRF group in men, but the same was not true in women.

\section{Association between adiposity and metabolic syndrome}

Anthropometric and metabolic parameters according to tertile of BMI are shown in Table 3. When participants were stratified into tertile based on their BMI, the levels of fasting glucose and HbA1c were found to be associated with BMI in women, but not in men. In general, the more obese participants had worse lipid profiles in both the men and women categories. The high BMI group had significantly higher triglycerides and a significantly lower HDL-C. The high BMI group had a significantly higher number of participants with metabolic syndrome when compared to the low BMI group in men and in women.

\section{Combined impact of BMI and CRF on the prevalence of metabolic syndrome}

To investigate the combined association of BMI and CRF with the prevalence of metabolic syndrome, the participants were stratified into nine subgroups, according to their BMI and CRF tertile (Figure 1).

Participants in the high BMI and low CRF group had 18.8 times (95\% CI: 5.0 - 70.5) and 8.1 times (95\% CI: 2.8 23.9) higher prevalence of metabolic syndrome in men and women, respectively. The prevalence of metabolic syndrome was reduced among participants in the high-BMI group if their CRF level was also high (OR: 7.9, 95\% CI: 2.031.2 for men, OR: 5.4, 95\% CI: 1.9-15.9 for women).

\section{Discussion}

Reductions in physical activity and CRF are associated with increased prevalence and incidence of metabolic syndrome. In our study, we found that a lower level of CRF, as indicated by slower HRR following exercise, was associated with increased prevalence of metabolic syndrome in Korean men. A low level of CRF is a known risk factor for both cardiovascular disease and type 2 diabetes; however, the importance of the current study is the use of HRR after submaximal exercise as a measure of CRF. A prior study has validated the Tecumseh step test as an appropriate 
Table 1 Characteristics of the study participants $(n=1007)$

\begin{tabular}{|c|c|c|c|c|}
\hline & Men $(n=488)$ & Women $(n=519)$ & Total $(n=1007)$ & $p$ Value \\
\hline \multicolumn{5}{|l|}{ Anthropometric } \\
\hline Age (years) & $51.11 \pm 13.93$ & $49.54 \pm 13.51$ & $50.30 \pm 13.74$ & 0.359 \\
\hline Height (cm) & $170.18 \pm 5.52$ & $158.06 \pm 5.70^{\#}$ & $163.93 \pm 8.26$ & 0.761 \\
\hline Weight (kg) & $71.54 \pm 10.01$ & $57.82 \pm 8.25^{\#}$ & $64.47 \pm 11.43$ & 0.038 \\
\hline BMI $\left(\mathrm{kg} / \mathrm{m}^{2}\right)$ & $24.61 \pm 2.69$ & $23.17 \pm 3.21^{\#}$ & $23.87 \pm 3.05$ & 0.001 \\
\hline Waist circumference (cm) & $84.44 \pm 7.07$ & $74.19 \pm 8.11^{\#}$ & $79.18 \pm 9.18$ & 0.004 \\
\hline \multicolumn{5}{|l|}{ Blood pressure } \\
\hline Systolic blood pressure (mmHg) & $125.08 \pm 12.23$ & $121.01 \pm 14.80^{\#}$ & $122.99 \pm 13.76$ & 0.001 \\
\hline Diastolic blood pressure $(\mathrm{mmHg})$ & $77.58 \pm 8.82$ & $72.18 \pm 9.80^{\#}$ & $74.80 \pm 9.71$ & 0.013 \\
\hline \multicolumn{5}{|l|}{ Blood variables } \\
\hline Glucose (mg/dl) & $104.33 \pm 24.40$ & $95.30 \pm 14.66^{\#}$ & $99.67 \pm 20.47$ & $<0.001$ \\
\hline Hemoglobin A1C (mg/dl) & $5.67 \pm 0.71$ & $5.67 \pm 0.75$ & $5.67 \pm 0.73$ & 0.46 \\
\hline Total cholesterol (mg/dl) & $192.47 \pm 33.12$ & $190.06 \pm 33.14$ & $191.23 \pm 33.13$ & 0.647 \\
\hline Triglycerides (mg/dl) & $153.27 \pm 95.90$ & $109.44 \pm 67.18^{\#}$ & $130.49 \pm 85.06$ & $<0.001$ \\
\hline Low-density lipoprotein (mg/dl) & $119.79 \pm 29.73$ & $120.44 \pm 30.65$ & $120.13 \pm 30.20$ & 0.185 \\
\hline High-density lipoprotein (mg/dl) & $45.66 \pm 10.80$ & $53.53 \pm 12.25^{\#}$ & $49.75 \pm 12.22$ & 0.008 \\
\hline \multicolumn{5}{|c|}{ Number of metabolic syndrome components } \\
\hline 0 & $105(21.5)$ & $49(9.4)$ & $154(15.3)$ & \\
\hline 1 & $146(29.9)$ & $198(38.2)$ & $344(34.2)$ & \\
\hline 2 & $117(24.0)$ & $149(28.7)$ & $266(26.4)$ & \\
\hline 3 & $71(14.5)$ & $84(16.2)$ & $155(15.4)$ & \\
\hline 4 & $24(4.9)$ & $25(4.8)$ & $49(4.9)$ & \\
\hline 5 & $13(2.7)$ & $5(1.0)$ & $18(1.8)$ & \\
\hline Metabolic syndrome & $110(22.9)$ & $119(23.1)$ & $229(22.7)$ & \\
\hline
\end{tabular}

Data are presented as means \pm SD or $N(\%)$.

$p$ values for categorical variables were determined from the Student's t-test for continuous data.

Number of MS components was not equal to actual number of participants with metabolic syndrome due to missing data (men: 12 ; women: 9).

${ }^{*} p<0.05$ vs. men, ${ }^{\#} p<0.01$ vs. men.

measurement to indicate cardiorespiratory fitness [34]. In comparison to the other more elaborate and expensive test approaches previously used to obtain $\mathrm{VO} 2$ max, the Tecumseh step test, used in the present study, is a relatively quick and easy method that can be used in most epidemiological and clinical settings [34]. Findings from the current study also indicate that the association between CRF and the prevalence of metabolic syndrome was somewhat gender dependent, although this relationship was less clear when the combined association of BMI and CRF with metabolic syndrome prevalence was examined.

The main finding of this study is the significant association between faster HRR after submaximal exercise and the lower prevalence of metabolic syndrome in men, suggesting that fitter men participants are at lower risk of metabolic syndrome. The association between CRF and metabolic syndrome has been reported previously. Laaksonen et al. [17] reported a significant inverse association between CRF and prevalence of metabolic syndrome even after adjustment for major confounders. In addition, Lamonte et al. [15] reported that the incidence of metabolic syndrome was significantly reduced among fit individuals (OR: 0.47, 95\% CI: 0.40 to 0.54 ) compared with the least fit individuals (lower tertile). The current study and previously reported studies suggest that fitter individuals are less likely to develop metabolic syndrome compared with those who are unfit. However, physical fitness is not the only contributor for the development of metabolic syndrome.

There are other factors independent of CRF that influence the development of metabolic syndrome. In our study, approximately $50 \%$ of obese individuals had metabolic syndrome. Similarly, several previous studies found that the components of metabolic syndrome were closely associated with obesity [10]. In a prospective cohort study, Katzmarzyk et al. [35] reported that overweight men were 4.5 times (95\% CI: 4.2-5.3) more likely to develop metabolic syndrome, and obese men were 30.6 times (95\% CI: 26.7-35.0) more likely to develop metabolic syndrome. It is not surprising that more obese individuals have a higher 
Table 2 Anthropometric and exercise characteristics of men (488) and women (519) according to tertile of BMI

\begin{tabular}{|c|c|c|c|c|c|c|c|c|}
\hline & \multicolumn{4}{|c|}{ Men $(n=488)$} & \multicolumn{4}{|c|}{ Women $(n=519)$} \\
\hline & $\begin{array}{c}\text { Low BMI } \\
\left(17.1-23.6 \mathrm{~kg} / \mathrm{m}^{2}\right)\end{array}$ & $\begin{array}{c}\text { Middle BMI } \\
\left(23.7-25.7 \mathrm{~kg} / \mathrm{m}^{2}\right)\end{array}$ & $\begin{array}{c}\text { High BMI } \\
\left(25.8-34 \mathrm{~kg} / \mathrm{m}^{2}\right)\end{array}$ & $p$ Value & $\begin{array}{c}\text { Low BMI } \\
\left(15.9-21.4 \mathrm{~kg} / \mathrm{m}^{2}\right)\end{array}$ & $\begin{array}{c}\text { Middle BMI } \\
\left(21.5-24 \mathrm{~kg} / \mathrm{m}^{2}\right)\end{array}$ & $\begin{array}{c}\text { High BMI } \\
\left(24.1-35.6 \mathrm{~kg} / \mathrm{m}^{2}\right)\end{array}$ & $p$ Value \\
\hline No. of participants & 162 & 166 & 160 & & 169 & 179 & 171 & \\
\hline \multicolumn{9}{|l|}{ Anthropometric } \\
\hline Age (years) & $51.06 \pm 15.49$ & $51.02 \pm 13.34$ & $51.24 \pm 12.94$ & 0.989 & $44.24 \pm 12.90$ & $49.21 \pm 13.23$ & $55.13 \pm 12.22$ & $<0.001$ \\
\hline Height (cm) & $170.48 \pm 5.41$ & $170.25 \pm 5.66$ & $169.79 \pm 5.50$ & 0.524 & $158.70 \pm 5.27$ & $157.74 \pm 5.12$ & $157.97 \pm 5.29$ & 0.215 \\
\hline Weight (kg) & $63.13 \pm 6.23$ & $71.76 \pm 4.66^{*}$ & $79.82 \pm 10.19^{* \#}$ & $<0.001$ & $50.41 \pm 5.47$ & $56.50 \pm 5.32^{*}$ & $66.64 \pm 5.49^{* \#}$ & $<0.001$ \\
\hline BMI $\left(\mathrm{kg} / \mathrm{m}^{2}\right)$ & $21.69 \pm 1.54$ & $24.74 \pm 0.60^{*}$ & $27.44 \pm 1.61^{* \#}$ & $<0.001$ & $20.05 \pm 1.65$ & $22.69 \pm 1.61^{*}$ & $26.73 \pm 1.67^{* \#}$ & $<0.001$ \\
\hline Waist circumference (cm) & $77.84 \pm 5.29$ & $85.07 \pm 3.99^{*}$ & $90.48 \pm 5.16^{* \#}$ & $<0.001$ & $67.70 \pm 4.77$ & $72.89 \pm 4.64^{*}$ & $81.99 \pm 4.78^{* \#}$ & $<0.001$ \\
\hline \multicolumn{9}{|l|}{ Blood pressure } \\
\hline Systolic blood pressure (mmHg) & $121.48 \pm 13.04$ & $124.95 \pm 10.44$ & $128.87 \pm 12.03^{* \#}$ & $<0.001$ & $116.78 \pm 12.94$ & $119.85 \pm 12.57$ & $125.75 \pm 12.99^{* \#}$ & $<0.001$ \\
\hline Diastolic blood pressure $(\mathrm{mmHg})$ & $74.75 \pm 9.18$ & $77.90 \pm 8.07$ & $80.10 \pm 8.41^{* \#}$ & $<0.001$ & $70.09 \pm 9.32$ & $71.74 \pm 9.06$ & $74.38 \pm 9.35^{* \#}$ & $<0.001$ \\
\hline \multicolumn{9}{|l|}{ Blood variables } \\
\hline Glucose (mg/dl) & $103.98 \pm 31.10$ & $102.96 \pm 20.94$ & $106.09 \pm 19.58$ & 0.502 & $92.07 \pm 14.66$ & $96.34 \pm 14.25^{*}$ & $97.38 \pm 4.71^{*}$ & 0.003 \\
\hline Hemoglobin A1C (mg/dl) & $5.67 \pm 0.81$ & $5.68 \pm 0.63$ & $5.67 \pm 0.68$ & 0.990 & $5.70 \pm 0.76$ & $5.76 \pm 0.75$ & $5.55 \pm 0.78^{\#}$ & 0.034 \\
\hline Total cholesterol (mg/dl) & $192.21 \pm 23.17$ & $194.51 \pm 34.51$ & $190.60 \pm 32.68$ & 0.563 & $190.79 \pm 34.22$ & $190.01 \pm 33.27$ & $189.76 \pm 34.34$ & 0.961 \\
\hline Triglycerides (mg/dl) & $127.91 \pm 86.02$ & $145.01 \pm 75.52$ & $187.15 \pm 133.32^{*}$ & $<0.001$ & $96.49 \pm 64.19$ & $104.67 \pm 62.43$ & $124.59 \pm 64.42^{* \#}$ & $<0.001$ \\
\hline Low-density lipoprotein (mg/dl) & $118.96 \pm 28.75$ & $122.89 \pm 31.55$ & $117.34 \pm 28.62$ & 0.230 & $120.15 \pm 31.59$ & $122.40 \pm 30.72$ & $119.02 \pm 31.70$ & 0.586 \\
\hline High-density lipoprotein (mg/dl) & $49.15 \pm 12.33$ & $45.19 \pm 10.60^{*}$ & $42.65 \pm 8.11^{* \#}$ & $<0.001$ & $57.43 \pm 12.20$ & $53.26 \pm 11.87^{*}$ & $50.24 \pm 12.24^{*}$ & $<0.001$ \\
\hline No.of participants with MS & $14(8.9)$ & $30(18.4)$ & $66(41.5)^{* \#}$ & $<0.001$ & $17(10.1)$ & $31(17.6)$ & $71(41.5)^{* \#}$ & $<0.001$ \\
\hline Odd ratio (95\% confidence interval) & 1 (reference) & $2.48(1.24-4.96)$ & $8.23(4.27-15.85)$ & & 1 (reference) & $1.63(0.86-3.11)$ & $4.64(2.53-8.53)$ & \\
\hline
\end{tabular}

Data are presented as means + SD or $N(\%)$.

All men and women participants were divided into three groups according to tertile of Body Mass Index, respectively.

One-way ANOVA was used to compare means of parameters between three groups in men. Post-hoc analysis: Scheffe.

Analysis of Covariance (ANCOVA) was used to compare means of parameters between three groups after age controlled for women. Post-hoc analysis: Bonferroni.

"significantly different between low BMI and middle BMI or significantly different between low BMI and high BMI, $p<0.05,1{ }^{\#}$ significantly different between middle BMI and high BMI, $p<0.05$.

significantly different between low BMI and middle BMI or significant
Abbreviations: BMI Body Mass Index, CRF Cardiorespiratory fitness. 
Table 3 Anthropometric and exercise characteristics of men (488) and women (519) according to tertile of heart rate recovery

\begin{tabular}{|c|c|c|c|c|c|c|c|c|}
\hline & \multicolumn{4}{|c|}{ Men $(n=488)$} & \multicolumn{4}{|c|}{ Women $(n=519)$} \\
\hline & $\begin{array}{c}\text { High CRF } \\
(53-82 \mathrm{bpm})\end{array}$ & $\begin{array}{l}\text { Moderate CRF } \\
(83-93 \text { bpm) }\end{array}$ & $\begin{array}{c}\text { Low CRF } \\
(94-137 \text { bpm) }\end{array}$ & $p$ Value & $\begin{array}{c}\text { High CRF } \\
(65-86 \text { bpm) }\end{array}$ & $\begin{array}{l}\text { Moderate CRF } \\
(87-97 \text { bpm) }\end{array}$ & $\begin{array}{c}\text { Low CRF } \\
(98-133 \text { bpm) }\end{array}$ & $p$ Value \\
\hline No. of participants & 163 & 162 & 163 & & 176 & 169 & 174 & \\
\hline \multicolumn{9}{|l|}{ Anthropometric } \\
\hline Age (years) & $52.56 \pm 14.04$ & $51.49 \pm 13.70$ & $49.26 \pm 13.95$ & 0.092 & $54.74 \pm 12.95$ & $48.31 \pm 13.45^{*}$ & $45.48 \pm 12.46^{*}$ & $<0.001$ \\
\hline Height (cm) & $169.62 \pm 5.50$ & $170.16 \pm 5.50$ & $170.75 \pm 5.54$ & 0.182 & $158.15 \pm 8.54$ & $158.14 \pm 5.17$ & $158.11 \pm 8.90$ & 1.000 \\
\hline Weight (kg) & $70.29 \pm 8.54$ & $72.53 \pm 11.82$ & $71.54 \pm 9.31$ & 0.121 & $56.42 \pm 13.68$ & $57.86 \pm 8.29$ & $59.18 \pm 14.27$ & 0.377 \\
\hline BMI $\left(\mathrm{kg} / \mathrm{m}^{2}\right)$ & $24.41 \pm 2.50$ & $24.82 \pm 2.70$ & $24.61 \pm 2.85$ & 0.391 & $22.62 \pm 5.05$ & $23.15 \pm 3.06$ & $23.62 \pm 5.26$ & 0.362 \\
\hline Waist circumference (cm) & $83.45 \pm 6.80$ & $84.90 \pm 7.02$ & $84.97 \pm 7.31$ & 0.089 & $72.71 \pm 12.02$ & $74.08 \pm 7.28$ & $75.58 \pm 12.52$ & 0.242 \\
\hline \multicolumn{9}{|l|}{ Blood pressure } \\
\hline Systolic blood pressure (mmHg) & $125.18 \pm 12.38$ & $124.07 \pm 11.46$ & $125.99 \pm 12.80$ & 0.368 & $119.69 \pm 21.63$ & $119.24 \pm 13.13$ & $122.73 \pm 22.56$ & 0.347 \\
\hline Diastolic blood pressure $(\mathrm{mmHg})$ & $76.50 \pm 8.93$ & $77.19 \pm 8.44$ & $79.05 \pm 8.93^{*}$ & 0.026 & $72.28 \pm 15.25$ & $71.13 \pm 9.26$ & $73.74 \pm 15.91$ & 0.287 \\
\hline \multicolumn{9}{|l|}{ Blood variables } \\
\hline Glucose (mg/dl) & $100.40 \pm 16.53$ & $102.20 \pm 20.95$ & $110.36 \pm 31.99^{* \#}$ & $<0.001$ & $94.17 \pm 23.94$ & $94.65 \pm 14.51$ & $96.95 \pm 24.97$ & 0.601 \\
\hline Hemoglobin A1C (mg/dl) & $5.67 \pm 0.68$ & $5.66 \pm 0.75$ & $5.68 \pm 0.70$ & 0.982 & $5.68 \pm 1.25$ & $5.61 \pm 0.75$ & $5.71 \pm 1.29$ & 0.409 \\
\hline Total cholesterol (mg/dl) & $192.33 \pm 33.54$ & $192.99 \pm 32.85$ & $192.08 \pm 33.16$ & 0.968 & $182.75 \pm 55.09$ & $192.22 \pm 33.40$ & $195.47 \pm 57.47$ & 0.136 \\
\hline Triglycerides (mg/dl) & $140.04 \pm 85.72$ & $162.97 \pm 109.63$ & $158.89 \pm 89.58$ & 0.086 & $103.56 \pm 105.30$ & $113.94 \pm 63.74$ & $107.88 \pm 109.82$ & 0.402 \\
\hline Low-density lipoprotein (mg/dl) & $120.46 \pm 29.70$ & $117.53 \pm 30.09$ & $121.36 \pm 29.47$ & 0.492 & $113.03 \pm 50.81$ & $123.42 \pm 30.81^{*}$ & $125.15 \pm 53.01$ & 0.061 \\
\hline High-density lipoprotein (mg/dl) & $48.23 \pm 13.02$ & $44.25 \pm 8.93^{*}$ & $44.47 \pm 9.58^{*}$ & 0.001 & $54.47 \pm 20.27$ & $53.67 \pm 12.27$ & $52.83 \pm 21.14$ & 0.851 \\
\hline No. of participants with MS & $26(23.6)$ & $39(35.5)$ & $45(40.9)^{*}$ & 0.035 & $39(22.4)$ & $37(21.9)$ & $43(24.9)$ & 0.392 \\
\hline Odd ratio (95\% confidence interval) & 1 (reference) & $1.78(1.01-3.15)$ & $2.40(1.37-4.22)$ & & 1 (reference) & $1.36(0.79-2.34)$ & $1.99(1.12-3.34)$ & \\
\hline
\end{tabular}

Data are presented as means $\pm S D$ or $N$

All men and women participants were divided into three groups according to tertile of Heart Rate Recovery, respectively.

One-way ANOVA was used to compare means of parameters between three groups in men. Post-hoc analysis: Scheffe.

Analysis of Covariance (ANCOVA) was used to compare means of parameters between three groups of women after age was controlled for. Post-hoc analysis: Bonferroni.

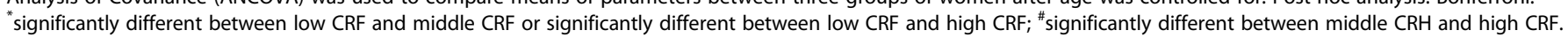
Abbreviations: HRR Heart rate recovery, CRF Cardiorespiratory fitness. 


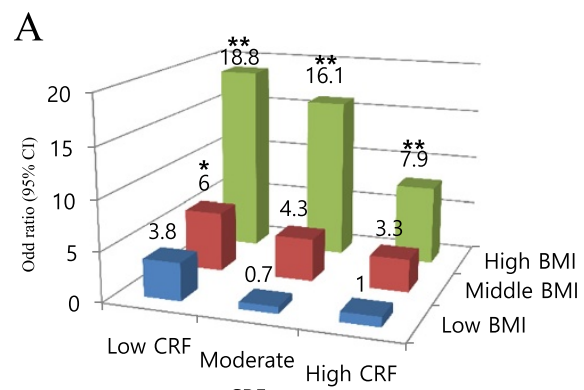

CRF

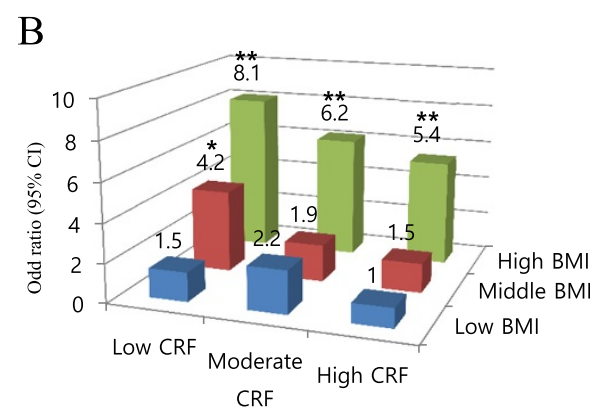

$\mathrm{CRF}$

Figure 1 Adjusted Odd ratio $(95 \% \mathrm{Cl})$ for metabolic syndrome according to cardiorespiratory fitness (CRF) and body mass index (BMI). (A) Men. (B) Women. Adjusted for age. Statistically significant different from reference group: ${ }^{*} p<.05,{ }^{* *} p<.01$. The participants were divided into nine groups according to tertile of their CRF and BMI. For BMI, the tertile ranges in men were: low BMl, 17.1-23.6; middle BMl, 23.7-25.7; high BMI, 25.8-34 kg/m²; and in women: low BMI, 15.9-21.4; middle BMI, 21.5-24; high BMI, 24.1-35.6 kg/m² For CRF, the tertile range in men: low CRF, 94-137; moderate CRF, 83-93; high CRF, 53-82 beats/min; and in women: low CRF, 98-133; moderate CRF, 87-97; high CRF, 65-86 beat/min.

prevalence of metabolic syndrome; one of the five metabolic syndrome components directly reflects degree of adiposity. In our study, we also confirmed that more obese individuals are more likely to have metabolic syndrome.

To further understand the combined association of obesity and CRF with the prevalence of metabolic syndrome, we have stratified our participants into nine groups according to their BMI and fitness levels. Compared with those who had low BMI and high CRF, those with high BMI and low CRF were 18.8 and 8.1 times more likely to have metabolic syndrome in men and women, respectively. It is noteworthy that among those with high BMI, fitter individuals of either gender have a lower risk of metabolic syndrome, suggesting the importance of fitness in the development of metabolic syndrome in Korean adults. For this study, CRF was indicated by the HRR measurement taken after administering the Tecumseh step test. Previous epidemiological studies have typically used the graded treadmill test or the $\mathrm{VO} 2$ max to measure CRF, when investigating the association between CRF and health-related outcomes. However, administering the $\mathrm{VO}_{2}$ max test requires specialized and expensive equipment, in addition to requiring well-trained technicians [34]. Recent studies indicate that CRF can more conveniently be assessed by measuring HRR after treadmill exercise. This HRR approach combined with treadmill exercise is a safe and inexpensive method, and has been proven to be valid [34-36]. An additional benefit from using the HRR approach lies in its demonstrated value in treating key components of metabolic syndrome, to include positive outcomes for fasting plasma glucose [37], HDL cholesterol [38-40], and insulin levels [41], and prevalence of type 2 diabetes mellitus [42]. Therefore, based on the findings from these studies [37-42], and supported by previously reported studies, we conclude that HRR following exercise is a safe and feasible method for estimating CRF in an epidemiological setting [28].

In our study, we have observed gender differences in the association of BMI and CRF with the components of metabolic syndrome. CRF was significantly associated with fasting glucose and $\mathrm{HbA1c}$ in men only, while BMI was significantly associated with fasting glucose and HbA1c in women only. The discrepancies found between genders could be due to the gender-specific distribution of adiposity and level of physical activity. Kriska et al. [36] reported that physical activity and physical fitness were associated with fasting glucose levels in men, but not in women. Authors speculated the reason for this gender difference was due to lower levels of physical activity in women participants. Indeed, in our previously reported study with the same cohort, we found significantly lower vigorous, moderate, and total physical activity levels in women participants compared with men [14]. Another explanation for the gender differences observed in our study could be the distribution of adiposity. Waist circumference and BMI were significantly lower among women participants compared with men participants in our study. Meanwhile, our women participants with high BMI still had significantly increased metabolic risk factors. The gender differences observed in our study require further investigation.

In understanding the mechanism of association between HRR and the prevalence of metabolic syndrome, independent and dependent of adiposity, it is necessary to understand the impact of parasympathetic and sympathetic nervous system activity on heart rate. The changes in cardiovascular function associated with low-intensity exercise are primarily mediated by parasympathetic withdrawal, and, as exercise intensity increases, additional cardiovascular reactivity is mediated by increased sympathetic outflow [37]. The fall in heart rate immediately after exercise is considered to be a function of the reactivation of the parasympathetic nervous system [38]. Delayed HRR after exercise could be related to attenuated parasympathetic reactivity, which has been described as a marker of decreased vagal activity [39]. Attenuated HRR induced by decreased vagal activity is a powerful risk factor for all-cause mortality [39-43]. 
The current study has several limitations. First, the level of HRR from the Tecumseh step test might be affected by BMI. The high BMI group could have an increase in heart rate that is greater than those of the other groups when they step up and down. Despite this limitation, this step test has been frequently used in clinical settings as a representative CRF test [44-46]. Second, due to the cross-sectional nature of this study, it was not possible to control some confounding factors as their diet and medications that may have affected the results. Factors that could have produced confounding influences included that the participants were recruited in this study by using convenience sampling, a relatively small sample size was used, and the limited age range for the group (middle age). Because of these biases and limitations, it is difficult to maintain that the findings of the present study accurately represent the Korean population in general.

\section{Conclusions}

In conclusion, we found that participants with a high level of CRF have lower risk of metabolic syndrome. The prevalence of metabolic syndrome increased as the degree of adiposity increased. However, high levels of CRF were associated with lower prevalence of metabolic syndrome among obese individuals. Our findings suggest the importance of physical fitness in the prevention of metabolic syndrome.

\section{Competing interests}

The authors declare that they have no competing interests.

\section{Authors' contributions}

JJ conceived and designed the study. HSH and LJA conducted the data analyses and drafted the manuscript. JJ led the drafting of manuscript and prepared the final version. All authors revised the manuscript for important content and have read and approved the final version.

\section{Acknowledgements}

The current study was supported by the National Research Foundation of Korea (NRF), Ministry of Education (No. 2011-0004892).

\section{Author details \\ ${ }^{1}$ Department of Sport and Leisure Studies, Sport Medicine Laboratory, Yonsei University, Seoul, Korea. ${ }^{2}$ Exercise Medicine Center for Diabetes and Cancer Patients, Yonsei University, Seoul, Korea. ${ }^{3}$ Anti-aging Center, Chaum Life Center, Cha Universty, Seoul, Korea. ${ }^{4}$ Department of Family Medicine, Kwandong University, College of Medicine, Gangneung-si, Republic of Korea. ${ }^{5}$ Sport and Medicine Research Center, INTOTO Inc, Seoul, Korea. ${ }^{6}$ Department of Clinical Nursing Science, Nursing Policy Research Institute, Yonsei University College of Nursing, Seoul, Korea. ${ }^{7}$ Department of Physical Education, Yonsei University, Seoul, Korea. ${ }^{8}$ Institute of Geriatric Medicine, Yonsei Woori Geriatric Hospital, Goyang, Gyeonggi-do, Korea.}

Received: 27 February 2014 Accepted: 6 May 2014

Published: 21 May 2014

\section{References}

1. Grundy SM, Brewer HB Jr, Cleeman JI, Smith SC Jr, Lenfant C, National Heart L, Blood I, American Heart A: Definition of metabolic syndrome: report of the National Heart, Lung, and Blood Institute/American Heart Association conference on scientific issues related to definition. Arterioscler Thromb VasC Biol 2004, 24(2):e13-e18.
2. Expert Panel on Detection E, Treatment of High Blood Cholesterol in A: Executive Summary of The Third Report of The National Cholesterol Education Program (NCEP) Expert Panel on Detection, Evaluation, And Treatment of High Blood Cholesterol In Adults (Adult Treatment Panel III). JAMA 2001, 285(19):2486-2497.

3. Hanson RL, Imperatore G, Bennett PH, Knowler WC: Components of the "metabolic syndrome" and incidence of type 2 diabetes. Diabetes 2002, 51(10):3120-3127.

4. Isomaa B, Almgren P, Tuomi T, Forsen B, Lahti K, Nissen M, Taskinen MR, Groop L: Cardiovascular morbidity and mortality associated with the metabolic syndrome. Diabetes Care 2001, 24(4):683-689.

5. Haffner SM, Valdez RA, Hazuda HP, Mitchell BD, Morales PA, Stern MP. Prospective analysis of the insulin-resistance syndrome (syndrome $\mathrm{X}$ ). Diabetes 1992, 41(6):715-722.

6. Mottillo S, Filion KB, Genest J, Joseph L, Pilote L, Poirier P, Rinfret S, Schiffrin EL, Eisenberg MJ: The metabolic syndrome and cardiovascular risk a systematic review and meta-analysis. J Am Coll Cardiol 2010, 56(14):1113-1132.

7. Nestel P, Lyu R, Low LP, Sheu WH, Nitiyanant W, Saito I, Tan CE: Metabolic syndrome: recent prevalence in East and Southeast Asian populations. Asia Pac J Clin Nutr 2007, 16(2):362-367.

8. Gu DF, Reynolds K, Wu XG, Chen F, Duan XF, Reynolds RF, Whelton PK, He J, Grp IC: Prevalence of the metabolic syndrome and overweight among adults in China. Lancet 2005, 365(9468):1398-1405.

9. Lim S, Shin H, Song JH, Kwak SH, Kang SM, Won Yoon J, Choi SH, Cho SI, Park KS, Lee HK, Jang HC, Koh KK: Increasing Prevalence of Metabolic Syndrome in Korea: The Korean National Health and Nutrition Examination Survey for 1998-2007. Diabetes Care 2011, 34(6):1323-1328

10. Despres JP, Lemieux I: Abdominal obesity and metabolic syndrome. Nature 2006, 444(7121):881-887.

11. Weiss R, Dziura J, Burgert TS, Tamborlane W, Taksali SE, Yeckel CW, Allen K, Lopes M, Savoye M, Morrison J, Sherwin RS, Caprio S: Obesity and the metabolic syndrome in children and adolescents. N Engl J Med 2004, 350(23):2362-2374.

12. Pan Y, Pratt CA: Metabolic syndrome and its association with diet and physical activity in US adolescents. J Am Diet Assoc 2008, 108(2):276-286. discussion 286.

13. Ford ES, Kohl HW 3rd, Mokdad AH, Ajani UA: Sedentary behavior, physical activity, and the metabolic syndrome among U.S. adults. Obes Res 2005, 13(3):608-614

14. Lee DH, Kim YM, Jekal Y, Park S, Kim KC, Naruse M, Kim SH, Kim SH, Park JH, Lee MK, Chu SH, Jeon JY: Low levels of physical activity are associated with increased metabolic syndrome risk factors in korean adults. Diabet Metab J 2013, 37(2):132-139.

15. LaMonte MJ, Barlow CE, Jurca R, Kampert JB, Church TS, Blair SN: Cardiorespiratory fitness is inversely associated with the incidence of metabolic syndrome - A prospective study of men and women. Circulation 2005, 112(4):505-512.

16. Ford ES, Li C: Physical activity or fitness and the metabolic syndrome. Expert Rev Cardiovasc Ther 2006, 4(6):897-915.

17. Laaksonen DE, Lakka HM, Salonen JT, Niskanen LK, Rauramaa R, Lakka TA: Low levels of leisure-time physical activity and cardiorespiratory fitness predict development of the metabolic syndrome. Diabetes Care 2002, 25(9):1612-1618

18. Wei M, Gibbons LW, Kampert JB, Nichaman MZ, Blair SN: Low cardiorespiratory fitness and physical inactivity as predictors of mortality in men with type 2 diabetes. Ann Intern Med 2000, 132(8):605-611.

19. Katzmarzyk PT, Church TS, Blair SN: Cardiorespiratory fitness attenuates the effects of the metabolic syndrome on all-cause and cardiovascular disease mortality in men. Arch Intern Med 2004, 164(10):1092-1097.

20. Church TS, Kampert JB, Gibbons LW, Barlow CE, Blair SN: Usefulness of cardiorespiratory fitness as a predictor of all-cause and cardiovascular disease mortality in men with systemic hypertension. Am J Cardio/ 2001 88(6):651-656.

21. Blair SN, Kohl HW 3rd, Barlow CE, Paffenbarger RS Jr, Gibbons LW, Macera CA: Changes in physical fitness and all-cause mortality, A prospective study of healthy and unhealthy men. JAMA 1995, 273(14):1093-1098.

22. Blair SN, Kohl HW 3rd, Paffenbarger RS Jr, Clark DG, Cooper KH, Gibbons LW: Physical fitness and all-cause mortality, A prospective study of healthy men and women. JAMA 1989, 262(17):2395-2401. 
23. Lee CD, Blair SN, Jackson AS: Cardiorespiratory fitness, body composition, and all-cause and cardiovascular disease mortality in men. Am J Clin Nutr 1999, 69(3):373-380.

24. Ross R, Katzmarzyk PT: Cardiorespiratory fitness is associated with diminished total and abdominal obesity independent of body mass index. Int J Obesity 2003, 27(2):204-210.

25. Janssen I, Cramp WC: Cardiorespiratory fitness is strongly related to the metabolic syndrome in adolescents. Diabetes Care 2007, 30(8):2143-2144.

26. Shephard RJ, Allen C, Benade AJ, Davies CT, Di Prampero PE, Hedman R, Merriman JE, Myhre K, Simmons R: The maximum oxygen intake, An international reference standard of cardiorespiratory fitness. Bull World Health Organ 1968, 38(5):757-764.

27. Petrella RJ, Koval JJ, Cunningham DA, Paterson DH: A self-paced step test to predict aerobic fitness in older adults in the primary care clinic. J Am Geriatr Soc 2001, 49(5):632-638.

28. Siconolfi SF, Garber CE, Lasater TM, Carleton RA: A simple, valid step test for estimating maximal oxygen uptake in epidemiologic studies. Am J Epidemiol 1985, 121(3):382-390.

29. Alberti KG, Zimmet P, Shaw J, Group IDFETFC: The metabolic syndrome-a new worldwide definition. Lancet 2005, 366(9491):1059-1062.

30. Alberti KG, Zimmet P, Shaw J: Metabolic syndrome-a new world-wide definition, A Consensus Statement from the International Diabetes Federation. Diabet Med 2006, 23(5):469-480.

31. Montoye HJ, Willis PW 3rd, Cunningham DA, Keller JB: Heart rate response to a modified Harvard step test: males and females, age 10-69. Res $Q$ 1969, 40(1):153-162.

32. Talbot LA, Morrell CH, Metter EJ, Fleg JL: Comparison of cardiorespiratory fitness versus leisure time physical activity as predictors of coronary events in men aged $\leq 65$ years and $>65$ years. Am J Cardiol 2002, 89(10):1187-1192.

33. Barnes DE, Yaffe K, Satariano WA, Tager IB: A longitudinal study of cardiorespiratory fitness and cognitive function in healthy older adults. J Am Geriatr Soc 2003, 51(4):459-465.

34. Reilly T, Tipton M: A sub-maximal occupational aerobic fitness test alternative, when the use of heart rate is not appropriate. Work 2010, 36(3):333-337

35. Katzmarzyk PT, Church TS, Janssen I, Ross R, Blair SN: Metabolic syndrome, obesity, and mortality: impact of cardiorespiratory fitness. Diabetes Care 2005, 28(2):391-397.

36. Kriska AM, Hanley AJ, Harris SB, Zinman B: Physical activity, physical fitness, and insulin and glucose concentrations in an isolated Native Canadian population experiencing rapid lifestyle change. Diabetes Care 2001, 24(10):1787-1792.

37. Kluess HA, Wood RH, Welsch MA: Vagal modulation of the heart and central hemodynamics during handgrip exercise. Am J Physiol Heart Circ Physiol 2000, 278(5):H1648-H1652.

38. Imai K, Sato H, Hori M, Kusuoka H, Ozaki H, Yokoyama H, Takeda H, Inoue M, Kamada T: Vagally mediated heart rate recovery after exercise is accelerated in athletes but blunted in patients with chronic heart failure. J Am Coll Cardiol 1994, 24(6):1529-1535.

39. Cole CR, Blackstone EH, Pashkow FJ, Snader CE, Lauer MS: Heart-rate recovery immediately after exercise as a predictor of mortality. $N$ Engl $J$ Med 1999, 341(18):1351-1357.

40. Jouven X, Empana JP, Schwartz PJ, Desnos M, Courbon D, Ducimetiere P Heart-rate profile during exercise as a predictor of sudden death. $N$ Engl J Med 2005, 352(19):1951-1958.

41. Cole CR, Foody JM, Blackstone EH, Lauer MS: Heart rate recovery after submaximal exercise testing as a predictor of mortality in a cardiovascularly healthy cohort. Ann Intern Med 2000, 132(7):552-555.

42. Cheng YJ, Lauer MS, Earnest CP, Church TS, Kampert JB, Gibbons LW, Blair SN: Heart rate recovery following maximal exercise testing as a predictor of cardiovascular disease and all-cause mortality in men with diabetes. Diabetes Care 2003, 26(7):2052-2057.

43. Chacko KM, Bauer TA, Dale RA, Dixon JA, Schrier RW, Estacio RO: Heart rate recovery predicts mortality and cardiovascular events in patients with type 2 diabetes. Med Sci Sports Exerc 2008, 40(2):288-295.
44. McArdle WD, Katch Fl, Pechar GS, Jacobson L, Ruck S: Reliability and interrelationships between maximal oxygen intake, physical work capacity and step-test scores in college women. Med Sci Sports 1972, 4(4):182-186.

45. Francis KT: Fitness assessment using step tests. Compr Ther 1987, 13(4):36-41.

46. Kim S, Kim JY, Lee DC, Lee HS, Lee JW, Jeon JY: Combined impact of cardiorespiratory fitness and visceral adiposity on metabolic syndrome in overweight and obese adults in Korea. PLoS One 2014, 9(1):e85742.

doi:10.1186/1471-2458-14-481

Cite this article as: Hong et al:: Association between cardiorespiratory fitness and the prevalence of metabolic syndrome among Korean adults: a cross sectional study. BMC Public Health 2014 14:481.

\section{Submit your next manuscript to BioMed Central and take full advantage of:}

- Convenient online submission

- Thorough peer review

- No space constraints or color figure charges

- Immediate publication on acceptance

- Inclusion in PubMed, CAS, Scopus and Google Scholar

- Research which is freely available for redistribution

Submit your manuscript at www.biomedcentral.com/submit
C) BioMed Central 